University of Maryland Francis King Carey School of Law

DigitalCommons@UM Carey Law

Maryland Law Review Online

$11-19-2013$

\title{
The Tobacco Diaries: Lessons Learned and Applied to Regulation of Dietary Supplements
}

Joanna K. Sax

Follow this and additional works at: https://digitalcommons.law.umaryland.edu/endnotes

Part of the Food and Drug Law Commons

\section{Recommended Citation}

Joanna K. Sax, The Tobacco Diaries: Lessons Learned and Applied to Regulation of Dietary Supplements , 73 Md. L. Rev. 20 (2013),

Available at: https://digitalcommons.law.umaryland.edu/endnotes/29

This Articles from Volume 73 is brought to you for free and open access by DigitalCommons@UM Carey Law. It has been accepted for inclusion in Maryland Law Review Online by an authorized administrator of

DigitalCommons@UM Carey Law. For more information, please contact smccarty@law.umaryland.edu. 


\section{THE TOBACCO DIARIES: LESSONS LEARNED AND APPLIED TO REGULATION OF DIETARY SUPPLEMENTS JOANNA K. SAX*}

\section{INTRODUCTION}

Little is known about adverse reactions to dietary supplements because these events are underreported. ${ }^{1}$ The Food and Drug Administration's ("FDA") ability to regulate dietary supplements has a long and complicated history, and the battle over regulation continues. $^{2}$ On a simple level, the debate over regulation of dietary supplements boils down to the FDA's charge to protect the public from harmful drugs and devices ${ }^{3}$ versus manufacturers' desire not to be regulated and individuals' autonomy to make decisions about what supplements to take. The arguments surrounding this debate are reminiscent of the debates surrounding the regulation of tobacco. The tobacco companies fought hard to keep the FDA out of regulating cigarettes; some members of the public argued that they should be allowed to take personal responsibility over the choice to use tobacco; and the FDA fought to bring tobacco within its regulatory authority.

Copyright (c) 2013 by Joanna K. Sax.

* Associate Professor of Law, California Western School of Law, J.D. University of Pennsylvania Law School, Ph.D. University of Pennsylvania School of Medicine. This Article was originally presented at Harvard Law School's Petrie-Flom Center for Health Law Policy, Biotechnology and Bioethics 2013 Annual Conference: The FDA in the 21st Century. The author thanks the editors of Maryland Law Review Endnotes for their excellent editing.

1. See Final Rule Declaring Dietary Supplements Containing Ephedrine Alkaloids Adulterated Because They Present an Unreasonable Risk, 69 Fed. Reg. 6788, 6817 (Feb. 11, 2004) (codified at 21 C.F.R. pt. 119) ("There is little doubt that dietary supplement adverse events are underreported.... There is no requirement that manufacturers of dietary supplements report such events to FDA. Moreover, the usual reporters of [adverse events], physicians, are often unaware of the events themselves or the person's history of dietary supplement use.").

2. For a brief history of the FDA's attempts to regulate dietary supplements, see Mark A. Kassel, From a History of Near Misses: The Future of Dietary Supplement Regulation, 49 FOOD \& DRUG L.J. 237, 249-60 (1994).

3. At present, dietary supplements are regulated as food, not drugs. See Dietary Supplement Health and Education Act, 21 U.S.C. \$321(ff) (2006) ("[A] dietary supplement shall be deemed to be a food within the meaning of this chapter.”). 
Although this Article is not about tobacco, an examination of the history of the tobacco industry's efforts to evade regulation is instructive. ${ }^{4}$ Tobacco, like many of the ingredients in dietary supplements, is natural. It is clear, however, that cigarettes, which contain tobacco, are harmful. This is also true of some dietary supplements. For example, some natural products, such as St. John's wort, can be harmful. ${ }^{5}$ Some additives to dietary supplements, such as ephedra or dimethylamylamine, can be harmful even though other ingredients in a product may be benign. ${ }^{6}$ The dietary supplement industry has many similarities to the tobacco industry-both utilize natural products, do not want to be heavily regulated, and have ingredients that are harmful or lethal. For these reasons, the history of the tobacco industry's efforts to avoid regulation is instructive in determining what role the FDA should play in the regulation of the dietary supplement industry.

This Article examines the future role of the FDA in the regulation of the dietary supplement industry. "A dietary supplement is a product taken by mouth that is intended to supplement the diet and that contains one or more "dietary ingredients.", Many consumers

4. See infra Part II.

5. See Marcus Mannel, Drug Interactions with St John's Wort: Mechanisms and Clinical Implications, 27 DRUG SAFETY 774, 788 (2004) ("Although evidence is rather weak, the risk of developing serotonin syndrome and other central adverse reactions cannot be ruled out. Therefore, combinations of St John's wort with psychotropic medications, in particular with serotonergic drugs (for example, SSRIs, tricyclic antidepressants, venlafaxine, tryptophan, tramadol, buspirone) and other antidepressants, should be used cautiously."); see, e.g., Risk of Drug Interactions with St. John's Wart and Indinavir and Other Drugs, U.S. FOOD \& DRUG ADMIN., http://www.fda.gov/Drugs/DrugSafety/PostmarketDrugSafetyInformationforPatientsand Providers/

DrugSafetyInformationforHeathcareProfession-

als/PublicHealthAdvisories/ucm052238.htm (last visited Nov. 17, 2013).

6. See FDA News Release P04-17, FDA Issues Regulation Prohibiting Sale of Dietary Supplements Containing Ephedrine Alkaloids and Reiterates Its Advice That Consumers Stop Using These Products (Feb. 6, 2004), available at http://www.fda.gov/NewsEvents/Newsroom/

PressAnnouncements/2004/ucm108242.htm ("[Ephedra] raises blood pressure and otherwise stresses the circulatory system. These effects are linked to significant adverse health outcomes, including heart attack and stroke."); Natasha Singer \& Peter Lattman, A Workout Booster, and a Lawsuit, N.Y. TIMES, Feb. 13, 2013, http:/ /www.nytimes.com/2013/02/14/business/death-after-use-of-jack3d-shows-gap-inregulation.html?pagewanted=all\&_r=0 ("In the medical literature, [dimethylamylamine] has often been described as a synthetic stimulant similar to amphetamines that can constrict blood vessels, raise blood pressure and heart rate, potentially increasing the risk of heart attacks and strokes.").

7. See infra Part III. FOOD

8. What Is the Difference Between a Dietary Supplement and a Conventional Food?, U.S. 
are not aware that dietary supplements are not regulated in the same manner as over-the-counter ("OTC") drugs." This misunderstanding is compounded by the fact that dietary supplements are often sold in the same store aisles as OTC drugs. ${ }^{10}$

Recent accounts report the harmful, even lethal, effects of ingesting certain dietary supplements. For example, multiple deaths have been linked to ingestion of a product called Jack3d, which contains dimethylamylamine and is marketed as a workout booster. ${ }^{11}$ The medical literature describes dimethylamylamine as a "synthetic stimulant similar to amphetamines." 12 After two soldiers who had used Jack3d died, the Department of Defense banned the product from being sold on military bases. ${ }^{13}$ Nevertheless, the product has not been removed from the shelves of General Nutrition Centers and other venues that sell dietary supplements. ${ }^{14}$ As one newspaper article suggests, the soldiers' deaths exemplify the shortcomings in the regulation of dietary supplements. ${ }^{15}$ Following the deaths, the FDA issued warning letters. ${ }^{16}$ Without definitive proof, the FDA's ability to ban the product is limited. ${ }^{17}$

Critics of the FDA's response to reports of adverse consequences of ingestion of Jack3d may not fully understand the limitations of the FDA's authority under the Dietary Supplement Health and Education Act of 1994 ("DSHEA"). ${ }^{18}$ Described in more detail below, the DSHEA provides that the FDA can respond to proof of harmful ingredients in dietary supplements. This is unlike the FDA's authority to

http://www.fda.gov/AboutFDA/Transparency/Basics/ucm194357.htm (last visited Oct. 29, 2013).

9. In a survey assessing beliefs and practices related to weight control, a substantial number of study participants assumed that the FDA reviews and approves dietary supplements for safety and efficacy before being sold to consumers. Janine L. Pillitteri et al., Use of Dietary Supplements for Weight Loss in the United States: Results of a National Survey, 16 OBESITY 790, 794 (2008).

10. $I d$.

11. Singer \& Lattman, supra note 6 .

12. Id.

13. Id.

14. Id.

15. Id.

16. $I d$.

17. Id.

18. Pub. L. No. 103-417, 108 Stat. 4325 (codified as amended in various sections of 21 and 42 U.S.C.). 
regulate drugs, whereby any drug that enters the marketplace must first receive FDA approval that it is safe and effective. ${ }^{19}$

As players in a $\$ 30$ billion per year industry, ${ }^{20}$ manufacturers of dietary supplements have incentive and money to fight against regulation. Regulation of dietary supplements in a manner similar to that of drugs means that manufacturers would have to apply to the FDA for approval prior to marketing their products. ${ }^{21}$ The time consuming and expensive FDA approval process could have an impact on the dietary supplement industry by raising prices to consumers (for the increased cost of approval) and/or by serving as a barrier to marketentry for some manufacturers. For these reasons, among others, the dietary supplement industry resists regulation.

Consumers may also have reasons to resist regulation over the dietary supplement industry. Consumers typically want to be able to choose whatever products they like without government interference. Some consumers believe that products promoted as "holistic" and "natural" are healthier alternatives to FDA approved drugs. ${ }^{22}$ Finally, consumers may appreciate the current lower costs of some dietary supplements as opposed to potential higher costs of FDA approved substances. ${ }^{23}$

The arguments against regulation made by manufacturers and consumers alike are premised on the basic principle of autonomy. These arguments are reminiscent of the arguments surrounding debates about regulation of tobacco. The tobacco industry argued that tobacco is a natural product and should not be regulated. ${ }^{24}$ Consumers/smokers argued for personal autonomy to use tobacco if they wished.

19. 21 U.S.C. $\$ 355$ (a) (2006); Development and Approval Process, U.S. FOOD \& DRUG ADMIN., http://www.fda.gov/Drugs/DevelopmentApprovalProcess/default.htm (last visited Oct. 29, 2013).

20. Singer \& Lattman, supra note 6.

21. See Development and Approval Process, supra note 19.

22. Michael A. McCann, Dietary Supplement Labeling: Cognitive Biases, Market Manipulation E्F Consumer Choice, 31 AM. J.L. \& MED. 215, 219 (2005).

23. One scholar cautions policymakers to consider the effects of mandating premarket testing of dietary supplements. $I d$. at 216. As this scholar notes, mandated premarket testing of all dietary supplements could mean that "many beneficial dietary supplements would be priced out of the reach of lower and middle income consumers who either have become users of those products or could become users." Id.

24. The tobacco industry then worked for decades to debunk data that established that smoking is harmful. See Lisa A. Bero, Tobacco Industry Manipulation of Research, 120 PUB. HEALTH REPORTS 200, 204 (2005) (describing how the tobacco industry paid consultants to criticize independent scientific research about tobacco's harmful effects). 
A concern addressed by this Article is not only the immediate safety risks associated with ingestion of unsafe dietary supplements, but also whether the dietary supplement industry is engaging in tactics to evade regulation that are similar to the tactics that the tobacco industry used. Regulators, researchers, and the public did not fully understand the web of deception employed by the tobacco industry until millions of pages of internal documents from the tobacco industry were released as part of the Master Settlement Agreement in $1998 .^{25}$ In ten, twenty, or thirty years, will we learn the same thing about the dietary supplement industry? How many adverse or lethal events must occur before Congress enacts legislation that provides the FDA with the authority to regulate the dietary supplement industry? Or will the dietary supplement industry continue to avoid regulation in much the same way as the tobacco industry has over the years?

To address the role of the FDA in the twenty-first century with respect to the dietary supplement industry, Part I of this Article begins by describing the dietary supplement industry and the role of the FDA in this industry. In Part II, this Article provides a brief exposé of the tactics used by the tobacco industry to evade regulation. The purpose of Part II is to provide insight into the tobacco industry's ability to manipulate consumers and discount scientific proof of the harmful effects of smoking. In Part III, this Article addresses solutions to concerns over the current regulatory regime. Although FDA regulation is likely the most effective way to ensure that products that are on the market are safe, Part III of this Article explores other non-regulatory mechanisms as well.

\section{OVERVIEW OF REGULATION OF DIETARY SUPPLEMENTS}

Since 1994, the dietary supplement industry has been minimally regulated by DSHEA. ${ }^{26}$ Before 1994, supplements were regulated as food additives and manufacturers were required to show that supplements were safe prior to entry into the market. ${ }^{27}$ In 1994, this regulatory scheme changed, and dietary supplements can now enter the

25. Id. at 200. For a brief history of the tobacco industry documents, see Lisa A. Bero, Implications of the Tobacco Industry Documents for Public Health and Policy, 24 ANN. Rev. PuB. HEALTH 267 (2003).

26. Pub. L. No. 103-417, 108 Stat. 4325 (codified as amended in various sections of 21 and 42 U.S.C.).

27. Pieter A. Cohen, American Roulette-Contaminated Dietary Supplements, 361 NEW ENG. J. MED. 1523, 1523-24 (2009). 
marketplace without pre-market testing of safety or efficacy. ${ }^{28}$ This scheme is unlike the approval process for pharmaceutical drugs, which must undergo years of clinical testing before being approved by the FDA and brought to market. ${ }^{29}$ Under the DSHEA, the FDA only has the authority to remove a dietary supplement from the market upon repeated reports of adverse reactions.

Advantages of minimal regulation of dietary supplements, as compared to drugs, include lower costs to the consumer, consumer choice, availability of alternatives, and health benefits. ${ }^{31}$ Nevertheless, the disadvantages associated with the minimal deregulation of dietary supplements abound-namely, direct and misleading marketing of harmful products to consumers and the lack of enforceable standards for dietary supplement ingredients. ${ }^{32}$

The term "dietary supplement" consists of a broad range of substances including vitamins, essential minerals, protein, amino acids, and herbs. ${ }^{33}$ Consumers are often surprised to learn that the supplements on the shelves of their local drug store are regulated differently than the OTC medicines that might be right next to them. ${ }^{34}$ That is, a multivitamin falls under the DSHEA, but Advil-right down the aisle-is a regulated drug. ${ }^{35}$ Many consumers do not understand this difference.

Dietary supplements are not intended to treat illness; they are to be used to supplement the diet. ${ }^{36}$ For this reason, labels on dietary

28. See $i d$. at 1524 ("Since the passage of the DSHEA, dietary supplements are presumed to be safe and can be marketed with very little oversight.").

29. McCann, supra note 22, at 215.

30. Id.

31. Id. at 219, 259.

32. Id. at 216 . One scholar proposes that "[a]ny optimal regulatory system for dietary supplements must... advance two essential, if competing, goals: 1) protect those most vulnerable from misleading health claims and unanticipated contents; and 2) enable an informed consumer class to purchase appreciably-beneficial products at predictable and affordable prices." Id. at 259.

33. Dietary Supplements: What You Need to Know, U.S. FOOD \& DRUG ADMIN., http://www.fda.gov/Food/ResourcesForYou/Consumers/ucm109760.htm (last visited Oct. 29, 2013).

34. Pillitteri, supra note 9 , at 794.

35. Multivitamins are the most popular dietary supplements in the United States; thirty-nine percent of adults used them in 2006. Madison Park, Half of Americans Use Supplements, CNN, Apr. 2011, http://www.cnn.com/2011/HEALTH/04/13/supplements.dietary/index.html.

36. See Dietary Supplements: What You Need to Know, supra note 33 ("Some supplements may help to assure that you get an adequate dietary intake of essential nutrients. However, 
supplements may not claim to treat, prevent, or cure diseases. ${ }^{37}$ Despite this restriction, many consumers turn to dietary supplements for these precise reasons. Some consumers like that the products claim to be "natural"; they may equate "natural" with "safe." "If a consumer would like to learn more about a particular supplement-for example, a list of adverse effects-he should contact the manufacturer, not the FDA. ${ }^{39}$

The dietary supplement industry is a $\$ 30$ billion per year industry. ${ }^{40}$ While many supplements are considered benign or even beneficial to consumers, ${ }^{41}$ this claim is hard to confirm or deny because the health effects of dietary supplements are rarely scientifically tested. Other dietary supplements, however, are likely harmful or deadly. ${ }^{42} \mathrm{~A}$ recent study illustrated that ingestion of several commonly used dietary supplements correlated with increased mortality risk. ${ }^{43}$ In this study, supplemental iron was closely associated with an increased risk of mortality in older women. ${ }^{44}$

Many consumers try dietary supplements to assist with weight loss. $^{45}$ In an industry-sponsored study, a research group surveyed 3,500 Americans about the use of dietary supplements for weight

supplements should not replace the variety of foods that are important to a healthful diet....").

37. Id.; U.S. DeP'T OF HeAlth \& Human SERvs., OfFICE OF THE INSPECTOR GEN., OEI01-11-00210, Dietary Supplements: Structure/Function Claims FaIL to MEeT FEDERAL REQUIREMENTS 16 (2012). Types of claims that are permitted on dietary supplement labels include nutrient content claims, health claims, and structure and function claims; the FDA's Center for Food Safety and Applied Nutrition is primarily responsible for overseeing claims made on dietary supplement labeling. Id. at 3.

38. Dietary Supplements: What You Need to Know, supra note 33.

39. Id.

40. Singer \& Lattman, supra note 6 .

41. McCann, supra note 22, at 215-16. 2011 ,

42. Eric Lipton, Support Is Mutual for Senator and Utah Industry, N.Y. TIMES, June 20,

http:/ /www.nytimes.com/2011/06/21/us/politics/21hatch.html?pagewanted=all\&_r=0 (noting that federal records between 2009 and 2011 show that 2,292 serious illnesses were reported by consumers using allegedly harmless nutritional supplements); Singer \& Lattman, supra note 6.

43. Jaakko Mursu et al., Less Is More: Dietary Supplements and Mortality Rate in Older Women, The Iowa Women's Health Study, 171 ARCH. INTERN. MED. 1625, 1631 (2011). The common dietary supplements associated with a higher risk of total mortality included multivitamins, vitamins $\mathrm{B}_{6}$ and folic acid, as well as minerals iron, magnesium, zinc, and copper. Id.
44. Id.
45. Pillitteri, supra note 9 , at 790 . 
loss. ${ }^{46}$ This study was sponsored by GlaxoSmithKline Consumer Healthcare, which received FDA approval for an OTC weight-loss drug. ${ }^{47}$ Presumably, the group was interested in learning about the use of weight-loss supplements and non-prescription drugs. The results of this study showed that respondents believed these supplements were approved for safety and efficacy prior to marketing. ${ }^{48}$ In addition, one-third of respondents believed that the weight-loss supplements were safer than OTC or prescription medications. ${ }^{49}$

Overall, this study showed that many respondents had misperceptions about the regulation of dietary supplements. ${ }^{50}$ Recent reports established that as many as one-hundred-forty dietary supplement products contain undeclared active pharmaceutical ingredients. $^{51}$ It is likely that this only represents a small fraction of contaminated supplements. $^{52}$ In addition, some manufacturers include pharmaceutical analogues in their products, which make detection of undeclared ingredients difficult. ${ }^{53}$ Some of these analogues may be dangerous to the users; but, in any event, the risks are unknown. ${ }^{54}$

In sum, the DSHEA limits the FDA's ability to regulate the dietary supplement industry. ${ }^{55}$ The FDA is limited in its ability to intervene until there are numerous adverse reports or it discovers pharmaceuticals in the supplement. ${ }^{56}$ Consumers have a lot of autonomy in deciding which supplements to take, although recent studies suggest that many consumers are not aware that the supplements are not preapproved by the FDA. ${ }^{57}$ The dietary supplement industry's resistance

\footnotetext{
46. $I d$.

47. Id. at 795 (see Acknowledgements).

48. Id. at 793 .

49. Id.

50. Id. at 793-94.

51. Cohen, supra note 27, at 1523.

52. Id.

53. Id. at 1524 .

54. Id.

55. See, e.g., id. at 1524 ("The DSHEA presents serious obstacles to the FDA's ability to detect and eliminate contaminated supplements.").

56. See McCann, supra note 22, at 215 (" $[\mathrm{M}]$ ost dietary supplements-like most foods-can immediately enter the market, and only after repeated instances of adverse reactions can the Food and Drug Administration ("FDA") remove them.").
}

57. Cohen, supra note 27, at 1524. 
to regulation ${ }^{58}$ is reminiscent of the tobacco industry's reaction to regulation by the FDA. ${ }^{59}$ For this reason, a summary of the tobacco industry's attempts to avoid regulation is instructive to explain how and why the FDA has limited authority to regulate the dietary supplement industry.

\section{TOBACCO INDUSTRY TACTICS TO AVOID REGULATION}

For decades, the tobacco industry has evaded and avoided real regulation by the FDA. Many of the arguments used by the dietary supplement industry to avoid regulation are similar to the strategies employed by the tobacco industry. A brief history of some of the major ways that the tobacco industry has remained elusive to regulatory control follows.

Decades ago, the tobacco industry organized as an interest group to employ strategies to suppress scientific research on the risks and harms of smoking. ${ }^{60}$ In 1998, internal documents detailing the tactics utilized by the tobacco industry were unveiled as part of the Master Settlement Agreement; ${ }^{61}$ since then, scholars have poured over these documents that reveal how the tobacco industry maintained credibility while generating doubts about the risks associated with smoking.

The tobacco industry funded research on smoking both by using its own scientists and by providing support to outside scientific consultants. ${ }^{62}$ As part of these efforts, the tobacco industry created the Council for Tobacco Research, which had the appearance of being independent even though it was not. ${ }^{63}$ In addition to funding research, the tobacco industry published and promoted findings that were favorable to its position. ${ }^{64}$ At the same time, the tobacco industry organized to suppress or criticize research that contained evidence that did not support its position. ${ }^{65}$ The tobacco industry interest group disseminated information to the media that contributed to the

58. See, e.g., Lipton, supra note 42 ("[Senator Orrin G.] Hatch ... has spent his career in Washington helping the [dietary supplement] industry thrive.... Mr. Hatch has repeatedly intervened with his colleagues in Congress and federal regulators in Washington to fight proposed rules that industry officials consider objectionable.").

59. See infra Part II.

60. Bero, supra note 24, at 200.

61. Id. at 201.

62. Id.

63. Id. at 201-02.

64. Id. at 202-03.

65. Id. at 204. 
lay press reporting that there was controversy about the risk of secondhand smoke, even though objective scientific studies were clear that secondhand smoke posed a health risk. ${ }^{66}$ Further, the tobacco industry promoted ventilation as an alternative to smoke-free environments by funding studies to rebut data about secondhand smoke. ${ }^{67}$ The tobacco industry attempted to use its research to influence policymakers. ${ }^{68}$

In addition to funding its own research, the tobacco industry fought hard to defund independent scientific research. ${ }^{69}$ In 1994, Dr. Stanton A. Glantz won a $\$ 598,686$ grant from the National Cancer Institute ("NCI") to study the effects of advocacy on tobacco policy. ${ }^{70}$ Internal documents showed that the tobacco industry created a plan to put pressure on the funding of "anti-tobacco" research. ${ }^{71}$ From 1994-1995, the tobacco industry utilized multiple outlets to attack the funding of Glantz's grant. ${ }^{72}$ In 1995, when the appropriations bill for the NCI came to the House floor for a vote, it contained language that would strip Glantz of his grant award from the NCI. ${ }^{73}$ The scientific community and its supporters petitioned politicians not to let the tobacco industry squash independent scientific inquiry. ${ }^{74}$ Nonetheless, the tobacco industry succeeded in convincing policymakers that the NCI should not fund or conduct some of the research provided for in Glantz's grant. The NCI informed the House Appropriations subcommittee that the NCI had ceased funding the portion of Glantz's grant related to campaign contributions. ${ }^{75}$ Disgusted by the government's decision, the American Cancer Society issued a grant to Glantz to continue that line of inquiry. ${ }^{76}$ Although, arguably, a badge of honor for an academic to be so vehemently opposed by the tobac-

66. Id.

67. J. Drope, S. A. Bialous, S. A. Glantz, Tobacco Industry Efforts to Present Ventilation as an Alternative to Smoke-Free Environments in North America, 13 TOBACCO CONTROL 41, 41-43 (2004).

68. Bero, supra note 24, at 204-05.

69. Anne Landman \& Stanton A. Glantz, Tobacco Industry Efforts to Undermine PolicyRelevant Research, 99 AM. J. OF PUB. HEALTH 45, 45 (2009).

70. Id. at 47 .

71. Id. at 48 .

72. Id.

73. Id. at 51 .

74. Id. at 51-52.

75. Id. at 52. The NCI did not reduce the grant; it merely shifted funds to the grant's other purposes. Id.

76. $I d$. 
co industry, this story sheds light on the intense public and political pressures waged by the tobacco industry against research aimed at demonstrating the effects of the tobacco industry on public health policy.

Use of the popular press is yet another tactic employed by the tobacco industry. For example, the tobacco industry created an industry front group known as the Associates for Research in the Science of Enjoyment ("ARISE") in order to use mass media to endorse the healthfulness of tobacco use. ${ }^{77}$ This group promoted the pleasures of smoking in moderation as similar to having dessert or a cup of coffee. ${ }^{78}$ The pleasure from smoking, the group suggested, is beneficial because it makes people happy. ${ }^{79}$

Direct-to-consumer marketing cannot be emphasized enough as a tobacco industry tactic, especially to younger people because they are at high risk for smoking initiation. ${ }^{80}$ Analysis of industry documents released pursuant to a settlement agreement reveal that the tobacco industry developed marketing strategies for each level of cigarette smoker, from those who are just beginning to experiment with cigarettes all the way to established smokers. ${ }^{81}$ These documents also reveal that the tobacco industry utilized research to implement its tactics. $^{82}$ For example, an internal memorandum from the tobacco company Philip Morris noted that a nonsmoker may become a smoker during times of stress. ${ }^{83}$ Young adults go through a series of stressful life events as they gain independence. ${ }^{84}$ The tobacco industry knew it could use this information to market to young adults that cigarettes help them relax during times of stress. ${ }^{85}$ The tobacco industry also focused on integrating smoking into activities associated with young adults, such as music and social gatherings. ${ }^{86}$

77. Elizabeth A. Smith, "It's Interesting How Few People Die from Smoking": Tobacco Industry Efforts to Minimize Risk and Discredit Health Promotion, 17 Eur. J. OF Pub. Health 162, 162 (2006).

78. Id. at $163,165-66$.

79. Id. at 165 .

80. Pamela M. Ling \& Stanton A. Glantz, Why and How the Tobacco Industry Sells Cigarettes to Young Adults: Evidence from Industry Documents, 92 AM. J. OF PUB. HEALTH 908, 908 (2002).

81. Id.

82. Id. at 909 .

83. Id. at 911 .

84. Id.

85. Id.

86. Id. at 913 . 
Finally, the tobacco industry spent enormous sums of money to maintain autonomy and undercut attempts by the government to regulate the industry. For example, the tobacco industry spent a reported $\$ 43$ million to lobby against tobacco legislation sponsored by Senator John McCain. ${ }^{87}$ In another tactic, a cigarette manufacturer withdrew all its advertising from a newspaper that printed an editorial in favor of tobacco control. ${ }^{88}$ This was a clear signal to the media not to promote tobacco regulation. ${ }^{89}$

In sum, the tobacco industry peppered the public with information that smoking is safe and pleasurable. ${ }^{90}$ Behind the scenes, the tobacco industry groups influenced politicians to avoid regulation and even defund smoking research. ${ }^{91}$ The tobacco industry successfully staved off regulation for decades. Even today, regulation of tobacco is minimal as many new and current smokers purchase cigarettes for consumption every day.

\section{REGULATORY AND NON-REGULATORY SOLUTIONS}

The manipulation of data and marketing techniques are not strategies singularly used by the tobacco industry. Other industries employ similar techniques to promote their products and cast doubt on data that demonstrates negative effects. ${ }^{92}$ A recent study analyzed whether the tobacco, pharmaceutical, lead, vinyl chloride, and silicosis-generating industries employed similar tactics to manipulate research. $^{93}$ Using corporate documents released through litigation, the study found that the tested industries used a variety of manipulation techniques, including:

(1) fund [ing] research that supports the industry's interests, (2) publish[ing] in scientific literature research that supports the industry's interests, (3) suppress[ing] industrysponsored research in cases where the results do not support

87. Yussuf Saloojee \& Elif Dagli, Tobacco Industry Tactics for Resisting Public Policy on Health, 78 Bulletin OF THE WORLD HEALTH ORG. 902, 906 (2000).

88. Id. at $905-06$.

89. Id.

90. See, e.g., Smith, supra note 77, at 163, 165-66 (describing the tobacco industry's public relations campaign to promote smoking as a pleasurable activity that is not harmful when enjoyed in moderation).

91. See, e.g., Landman \& Glantz, supra note 69, at 47-52 (describing the tobacco industry's efforts to defund research and influence legislation).

92. Jenny White \& Lisa A. Bero, Corporate Manipulation of Research: Strategies Are Similar Across Five Industries, 21 STAN. L. \& POL'Y REV. 105, 106 (2010).

93. Id. 
the industry's interests, (4) distort[ing] public discourse on research that does not support the industry's interests, (5) set[ting] scientific standards that favor the industry's interests, and (6) disseminat[ing] favorable research directly to decision-makers and the public. ${ }^{94}$

All of these industries faced litigation over health-related issues; all of these industries released documents that provided information that they used a variety of the six techniques listed above. ${ }^{95}$

At this time, it may be impossible to know if the dietary supplement industry is utilizing the same techniques as the tobacco, pharmaceutical, lead, vinyl chloride, and silicosis-generating industries. Members of the dietary supplement industry employ consultants to assist in their cause. ${ }^{96}$ Members of the dietary supplement industry have relationships with members of Congress. ${ }^{97}$ Dietary supplements are marketed to consumers; for example, a number of dietary supplements are advertised as assisting in weight loss. ${ }^{98}$ It is unclear whether the dietary supplement industry is colluding to fund research that supports its position.

Providing the authority for the FDA to regulate dietary supplements is the most conservative and most likely effective way to ensure that safe products are available to the public. There are, however, caveats to this solution. It is likely that many supplements that are on the market do not require heavy-handed regulation. ${ }^{99}$ For example, should Vitamin C be regulated in the same manner as Jack3d, which contains dimethylamylamine ${ }^{100}$ A regulatory scheme for dietary supplements should consider the magnitude of the risk in different categories of dietary supplements. ${ }^{101}$

94. Id. at 108 .

95. Id. at 109.

96. See, e.g., ContinuUm Partner Consulting, http://www.continuumpartner.com/ about.html (last visited Mar. 1, 2013) ("Continuum Partner Consulting provides services in ... regulatory compliance, especially dietary supplement . . compliance ....”).

97. See, e.g., Lipton, supra note 42 (describing how Senator Orrin G. Hatch has gained the support of the dietary supplement industry).

98. See, e.g., GNC, http://www.gnc.com/category/index.jsp?categoryId=3593188 (last visited Mar. 1, 2013) (marketing products for appetite control, meal replacements, and diet support).

99. See McCann, supra note 22, at 215 ("[M] any dietary supplements have proven not only safe, but reasonably effective.").

100. Singer \& Lattman, supra note 6.

101. Cf. McCann, supra note 22, at 216 (proposing an approach to dietary supplement labeling that would distinguish supplements "on the basis of potential risk and anticipated benefit"). 
The FDA is not the only way to regulate the dietary supplement industry. State and local regulations have been used to temper the tobacco industry. ${ }^{102}$ Examples of these regulations include enacting smoke-free indoor air laws and minimum age limits for purchasing tobacco products. ${ }^{103}$ In addition, settlements in litigation with the tobacco industry have placed limits on advertising and other marketing and have imposed requirements to reduce youth access to tobacco. ${ }^{104}$

Similarly, non-FDA strategies can be used to inform the public about dietary supplements. Local and state regulations, similar to the ones applied to cigarettes, can be employed. In addition, perhaps the Federal Trade Commission could be granted the authority to direct manufacturers of dietary supplements to include warnings that communicate effectively the potential harms from taking a dietary supplement. $^{105}$

Taxes are another way to regulate the industry. State and local authorities can increase taxes on the sale of dietary supplements, much in the same way that cigarettes are taxed. The increased price, through taxation, will deter some consumers from purchasing dietary supplements. This approach, however, has multiple limitations. First, it is a regressive tax that disproportionately affects low-income people, who are large users of dietary supplements. ${ }^{106}$ Second, it does nothing to address the safety concerns. Finally, it is probably not a strong enough policy to have the dis-incentivizing effects that it might intend to have.

Overall, the dietary supplement industry is winning the game of chess. ${ }^{107}$ If Congress attempts to propose legislation granting the FDA authority to regulate the industry, the dietary supplement industry maneuvers in a way to ensure the congressional attempt will be unsuccessful. ${ }^{108}$ This is the same game played by the tobacco industry. ${ }^{109}$

102. Michael Givel \& Stanton Glantz, The "Global Settlement" with the Tobacco Industry: 6 Years Later, 94 AM. J. OF PUB. HeAlth 218, 220-21 (2004).

103. Id.

104. Id. at 219-20.

105. See McCann, supra note 22, at 250 (“[D]ietary supplement advertisements in books, magazines, mailings, infomercials, and other television and radio commercials fall under the jurisdiction of the Federal Trade Commission ("FTC").").

106. Id. at 224 .

107. See supra Part I.

108. See, e.g., Lipton, supra note 42 (describing how the dietary supplement industry fought a proposed law that would give the FDA more power to regulate dietary supplements).

109. See supra Part II. 
The exact nature of the dietary supplement industry's tactics will not be known until there is extensive litigation and a release of corporate documents. It was only after the release of corporate documents in other industries that we learned the details of industry tactics to avoid regulation. ${ }^{110}$

This Article suggests that we should not have to wait until litigation forces the release of corporate documents in order to learn if the dietary supplement industry is utilizing some of the same tactics as the tobacco industry. Some dietary supplements are causing harm to consumers and the role of the FDA should be expanded to protect the public by ensuring that dietary supplements are safe.

\section{CONCLUSION}

As the saying goes: "Fool me once, shame on you. Fool me twice, shame on me." Industries that do not want to be regulated employ similar tactics to avoid regulation. ${ }^{111}$ Some products in the dietary supplement industry have proven to be harmful. While it may be over-inclusive to regulate the entire industry, doing so will mean that consumers are more likely to purchase safe products. We can learn lessons from the big profit-earning tobacco industry and its tactics to avoid regulation, and we can apply those lessons to the dietary supplement industry. In the twenty-first century, the FDA should be granted the authority to regulate the dietary supplement industry.

110. White \& Bero, supra note 92, at 105-06.

111. Id. at 108 . 